\title{
Effects of season and regulated photoperiod on the reproductive performance of sows
}

\author{
T.C. Chokoe ${ }^{1,2}$ and F.K. Siebrits ${ }^{2 \#}$ \\ ${ }^{1}$ ARC, Department of Reproduction Genetic Resources, Irene Animal Improvement Institute, Private Bag X02, \\ Irene 0062, South Africa \\ ${ }^{2}$ Tshwane University of Technology, Department of Animal Sciences, Private Bag X680, Pretoria 0001, South Africa
}

\begin{abstract}
Reproductive performance of experimental commercial Dalland sows $(n=87)$ maintained under a constant photoperiod $(10 \mathrm{~h}$ light and $14 \mathrm{~h}$ darkness) and control sows $(\mathrm{n}=187)$ maintained under natural daylight length ( $10.4 \mathrm{~h}$ light in winter and $13.4 \mathrm{~h}$ light in summer) were compared. In early summer $4.1 \%$ of experimental sows returned to oestrus compared to $20.8 \%$ of the control sows. In late summer $9.1 \%$ of experimental sows returned to oestrus compared to $21.9 \%$ of the control sows. Reduced photoperiod improved the farrowing rate of experimental sows in the early summer breeding compared to the control group (95.4\% and $81.3 \%$, respectively). With winter breeding there was a small proportion of sows that returned to service in both groups $(7.9 \%$ and $8.9 \%)$ while the farrowing rate was high in both groups $(93.9 \%$ and $91.0 \%$ in the experimental and control groups, respectively). Litter sizes derived from early summer services were 11.4 and 11.6 for the experimental and control groups, respectively, while winter services led to litter sizes of 11.6 and 12.4 whereas in late summer services, regulated photoperiod had improved the litter size of the experimental group (12.3) compared to the control group (11.2).
\end{abstract}

Keywords: Season, regulated photoperiod, return to oestrus, farrowing rate, litter size

${ }^{\#}$ Corresponding author. E-mail: siebritsfk@tut.ac.za

\section{Introduction}

Summer infertility continues to reduce the overall reproductive performance and economic efficiency in pig herds in South Africa and elsewhere. Research and investigations (Prunier et al., 1996; Gaustad-Aas et al., 2004) with regard to lower reproduction performance during the past 20 years have shown that virtually every aspect of male and female pig reproduction is adversely affected during summer.

Photoperiod has been generally recognized as the primary determinant of seasonality in pig breeding. Daylight length change provides the most reliable cue of season and is the environmental factor used by most species of animals to determine the breeding season when survival of offspring is most favourable. Increasing daylight length before the summer season evidently regulates seasonal changes in fertility of sows, but results of studies on the effect of photoperiod on pituitary gonadotrophin production (Love et al., 1993) are inconsistent. Several studies have indicated that the levels of the follicle stimulating hormone (FSH) and luteinizing hormone (LH), the most important hormones affecting fertility, showed clear seasonal patterns (Love et al., 1995; Peltoniemi et al., 1997a; Bassett et al., 2001). During summer the levels of these hormones are low while in winter increased levels are observed. It is generally accepted that plasma melatonin levels increase during the hours of darkness while light suppresses its synthesis and release from the pineal gland (Malpaux et al., 1988; 1999). The pattern of melatonin secretion transduces information of lighting conditions to the endocrinological control system of gonadotrophins in the hypothalamus (Malpaux et al., 1996; 1999). A circadian secretion pattern of melatonin in the domestic pig is similar to that of the European wild boar (Sus scrofa), which is a short day breeder (Mauget, 1982; Tast et al., 2001a). There is preliminary evidence that reduced fertility traits due to changes in day length can be corrected by a simple and effective light programme (Foxcroft, 1997).

The most common manifestation of seasonal infertility encountered in the pig industry includes delayed puberty in gilts, prolonged weaning to oestrus interval, reduced farrowing rate and reduced litter size which occur more frequently during late summer and early autumn than in the winter-spring season (Pepin \& Mauget, 1989; Peterson \& Pearce, 1990; Love et al., 1995; Quesnel \& Prunier, 1995; Prunier et al., 1996; Peltoniemi et al., 1999). The effect of season is regarded as an important environmental component causing 
variation in sow fertility (Tantasuparuk et al., 2000). Factors related to the climatic variables (photoperiod, temperature and humidity), nutrition and management techniques (lactation length, social environment and boar exposure) have an effect on the decreased reproductive efficiency in sows (Quesnel \& Prunier, 1995).

Gaustad-Aas et al. (2004) found that seasonal photoperiod differences due to latitude differences, manifested in different litter sizes and farrowing rates although temperatures were more or less constant and within the thermal neutral zone for sows. Tummaruk et al. (2007) found that the proportion of gilts exhibiting first oestrus was lowest during summer $\left(36.3 \pm 2.0^{\circ} \mathrm{C}\right.$ average maximum) compared to winter $\left(35.0 \pm 1.6^{\circ} \mathrm{C}\right.$ average maximum) and rainy season $\left(34.5 \pm 1.9^{\circ} \mathrm{C}\right.$ average maximum). Paterson et al. (1978) confirmed that when the mean maximum temperature exceeded $32{ }^{\circ} \mathrm{C}$ during the time of mating, a higher than normal proportion of infertile sows was observed. This infertility was associated with an increased number of sows returning to oestrus. Therefore, it appears that sows are sensitive to elevated temperatures at or around time of mating. Dan \& Summers (1996) found that farrowing rates were higher when sows were mated during the cooler season in Australia, and during the hot and dry season compared to the hot and humid season in Vietnam. Conversely, Paterson et al. (1978) found no evidence of a relationship between temperature at mating and average litter size, which remains more or less constant throughout the year. Lahrman \& Gardner (1997) concluded that neither photoperiod nor temperature had any substantial effect on sow fertility in well-managed German herds.

The present study was conducted to determine the reproductive performance of sows housed under regulated photoperiod conditions compared to sows housed under natural light conditions. It was hypothesized that reduced daylight will improve oestrus expectancy rates of sows seven days after weaning, non-return rate, farrowing rates and litter size.

\section{Materials and Methods}

The study was conducted in a commercial pig herd consisting of the Dalland breed, located at BelaBela in the Limpopo Province of the Republic of South Africa (Latitude: $-24^{\circ} 09^{\prime} 00^{\prime \prime}$; Longitude: $28^{\circ}$ 33'00"; Altitude: $1143 \mathrm{~m}$ ). The study encompassed four different stages viz. winter, early summer (including spring), late summer (including autumn) and winter, from April 2002 to December 2003 (Table 1). Two groups of sows (control and experimental) were used for each season of the study. All animals used in this study were randomly selected and only sows of second to fourth parities were used. In this study sow fertility was defined as a sow reaching puberty at a reasonably early age ( 8 months), being able to conceive and farrow the target litter size in terms of total number of piglets born. The selected sows of the experimental group were transferred to a separate building used for dry sows. This building was equipped with an additional ventilation system as well as curtains to obtain a regulated photoperiod. The control group was kept in the dry sow house under standard farming conditions, with natural daylight length. After weaning the experimental sows (87) were transferred to the regulated photoperiod dry sow house. The remaining sows (187) were treated as a control group and were housed in the standard dry sow house.

Table 1 Experimental design of the study

\begin{tabular}{clcc}
\hline Stages of the study & Period & $\begin{array}{c}\text { Regulated photoperiod } \\
(\mathrm{n}=\text { sows })\end{array}$ & $\begin{array}{c}\text { Natural photoperiod } \\
(\mathrm{n}=\text { sows })\end{array}$ \\
\hline Stage 1 & Winter 2002 & - & 275 \\
Stage 2 & Early summer and spring 2002 & 87 & 187 \\
Stage 3 & Late summer and autumn 2003 & 87 & 154 \\
Stage 4 & Winter 2003 & 83 & 121 \\
\hline
\end{tabular}

Meteorological information was obtained from the Weather Services at the Towoomba weather station located near the experimental site. For the duration of the study the control sows kept under natural photoperiod conditions were housed in individual crates in an open-sided building (100 m x $17 \mathrm{~m})$. They were exposed to a minimum daylight cycle of $10.4 \mathrm{~h}$ during winter and a maximum of $13.4 \mathrm{~h}( \pm 15 \mathrm{~min})$ during summer. A Hagner EC1 light meter (Hagner, Sweden) was used to measure light intensity. The 
ventilation system that was used consisted of four fans (Cumberland, model: CEVS50). All four fans had a thermostat with an automatic "on and off" switch that controls ventilation. The ventilation system delivered an air volume of $382 \mathrm{~m}^{3}$ per min at a frequency of $10 \mathrm{~min}$ on and $5 \mathrm{~min}$ off, depending on the temperature. Temperature was recorded daily, using alcohol minimum/maximum thermometers, suspended from the roof of the house, $0.4 \mathrm{~m}$ above the floor situated at different locations in the house.

The experimental dry sow house ( $30 \mathrm{~m} \times 10 \mathrm{~m})$ was equipped with black polyvinyl chloride curtains, which completely excluded light. The curtains were opened and closed manually. During the day the only light source in the house was that from the sun. Sows were exposed to light from 07:30 to 17:30 by opening the curtains and to darkness from 17:30 to 07:30 by closing the curtains. This system provided $10 \mathrm{~h}$ light and

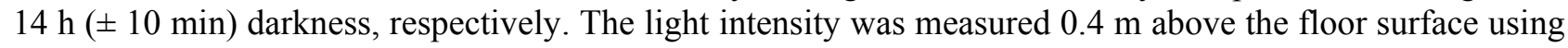
a light meter (Hagner model EC1, Sweden). The automatic ventilation system consisted of three fans (Cumberland, model: Perricoli). These fans were installed to limit extremes in temperature variation (in both the experimental and control houses) by increasing ventilation. One fan sucked and circulated the air into the house while the other two sucked the air out of the house. The working frequencies (on and off) of the fans were controlled by a thermostat. The ventilation system was able to deliver airflow of $283 \mathrm{~m}^{3}$ per minute with a frequency of $10 \mathrm{~min}$ on and $5 \mathrm{~min}$ off, depending on the temperature.

All sows were inseminated and remained in their respective dry sow houses (control and experimental) for the entire gestation period. On the $110^{\text {th }}$ day of gestation sows were moved to the farrowing house, which was under standard farm conditions. Piglets were weaned at the end of a lactation period of $28( \pm 2)$ days. Experimental sows were moved back to their experimental dry sow house while the control sows were moved to their control dry sow house. This procedure was repeated until the end of the study.

A batch farrowing system was implemented. Twenty two to 70 litters were weaned every second week after a $28( \pm 2)$ day lactation period. Sows were kept in their individual crates in their respective allocated dry sow houses. Just prior to oestrus, a boar was moved among the pens to have contact with the sows. Oestrus detection was performed twice daily, in the morning (08:00) and in the afternoon (16:00), by an experienced technician applying a backpressure test on each sow. All animals were inseminated in the mornings (09:00) when in standing oestrus, and re-inseminated in the afternoon (15:00). Pooled semen from different Dalland boars of Boar Line 80 was used. The semen was obtained from an official AI station (Topigs SA). Repeated inseminations during the same oestrus were considered as a single insemination event.

Pregnancy diagnosis was performed from the $15^{\text {th }}$ to the $22^{\text {nd }}$ day after insemination by means of a backpressure test, in the presence of a boar (control of repeat breeding). On the $25^{\text {th }}$ day after insemination, a transcutaneous real time ultrasound (Tringa 5OS) equipped with a linear probe set at $3.5 \mathrm{MHz}$ was used to detect pregnancy. Animals were regarded as pregnant when embryonic sacs were detected by ultrasound examination.

All farrowings were recorded and supervised twice daily during working hours (07:00 to 17:00). Number of piglets born alive and total litter weights were recorded. Cross fostering was applied during working hours after most sows had finished farrowing. No intensive culling due to small litter size was practiced.

Data pertaining to the piglet's birth were analysed using one-way analysis of variance (ANOVA). The reproductive traits of sows such as conception rate, return to oestrus/service, farrowing rate and weaning-toservice interval (WSI) were classified according to the season, as well as for the experimental and control group. Chi-square tests were performed on these reproductive sets of data, to test for differences in proportions found per reproductive trait. Number of piglets born per litter was analysed by a two-way ANOVA testing for differences between the treatment effects and season effects using the statistical programme, GenStat (2000). Treatment means were separated using Fishers' protected t-test least significant difference (LSD) at the $5 \%$ level of significance.

\section{Results}

The pattern of variation in light duration for the experimental sows housed in a building with a regulated photoperiod and control sows housed in a building with a normal photoperiod is presented in Figure 1 along with average maximum temperatures inside the houses. 


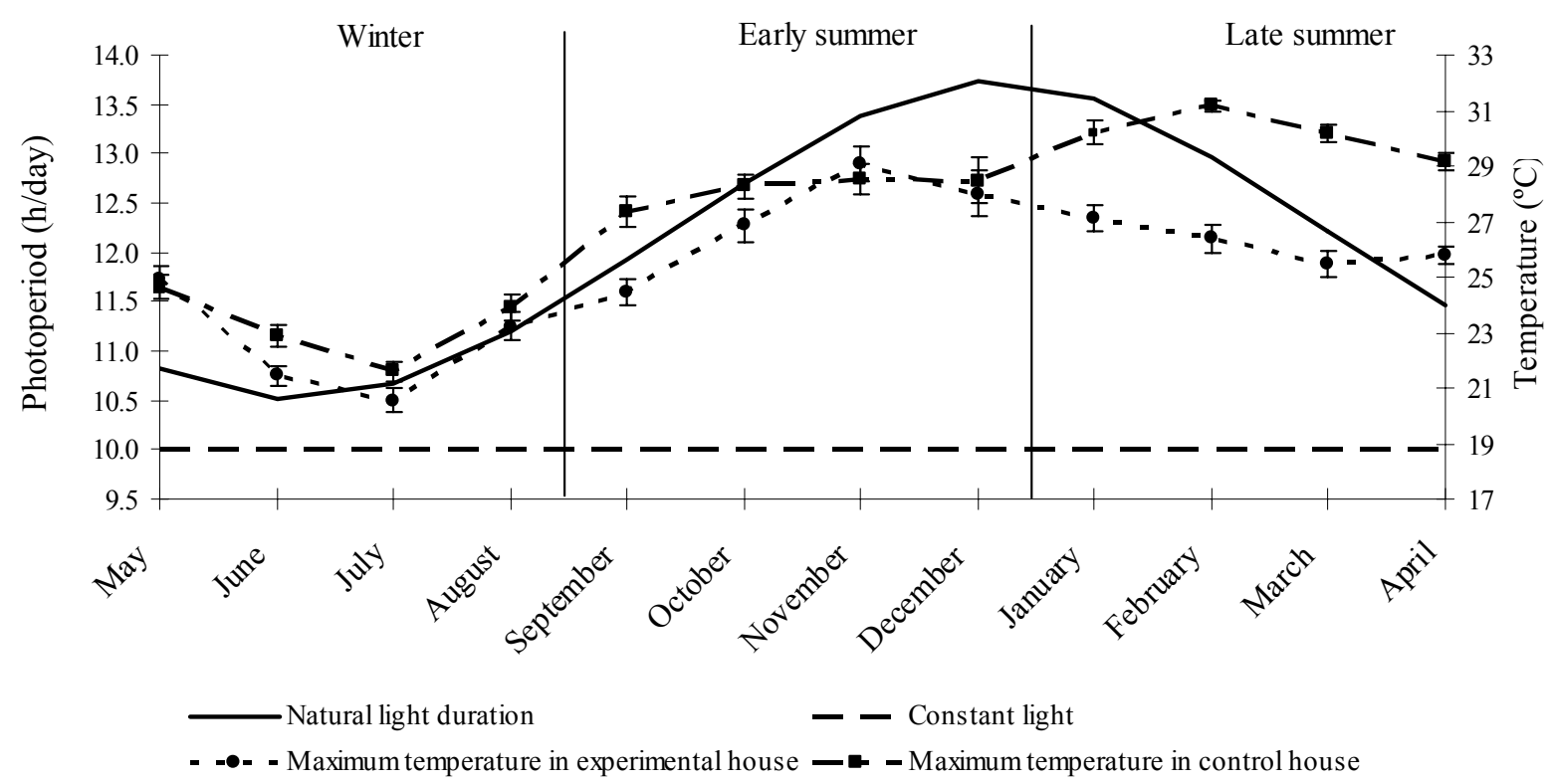

Figure 1 Pattern of variation in light duration (h/day) during the trial period for experimental and control sows (source: SA Weather Services) and average temperatures in sow houses.

Maximum daylight length was $13.39 \mathrm{~h}$ in summer (Figure 1) while the shortest day was $10.37 \mathrm{~h}$. The control group was exposed to the natural light durations of the different seasons while the experimental group was exposed to a regulated $10 \mathrm{~h}$ photoperiod throughout the whole study. The light intensity in the control house was more than 300 lux during clear days and 60 - 90 lux when measured during cloudy days. The light intensity in the experimental house was more than 300 lux when the curtains were open and 0 - 30 lux when the curtains were close. The average maximum temperature in the experimental house was $25.2 \pm$ $3.2{ }^{\circ} \mathrm{C}$ compared to $27.1 \pm 3.9{ }^{\circ} \mathrm{C}$ in the control house. The temperature during the late summer months, January, February, March and April, was on average $4{ }^{\circ} \mathrm{C}$ higher in the control house than in the experimental house while the differences were $1.05^{\circ} \mathrm{C}$ in early summer and $0.7^{\circ} \mathrm{C}$ in winter.

Table 2 Frequencies of sows kept under regulated $(10 \mathrm{~h})$ or natural photoperiod served less or more than seven days post-weaning during different seasons

\begin{tabular}{lccc}
\hline \multirow{2}{*}{ Seasons } & \multicolumn{2}{c}{ Number of sows } & $\chi^{2}$-value \\
& \multicolumn{2}{c}{$8.56^{1}$} \\
\cline { 2 - 3 } & Regulated photoperiod & Natural photoperiod & \\
Early summer & 87 & 188 & \multirow{2}{*}{$6.67 \mathrm{~ns}^{2}$} \\
No. weaned & $75(86.2 \%)^{2}$ & $180(95.7 \%)$ & \\
No. served $1-7$ days & $12(13.8 \%)$ & $8(4.3 \%)$ & \\
No. served $>7$ days & 87 & 175 & $0.01 \mathrm{~ns}$ \\
Late summer & $84(96.6 \%)$ & $167(95.4 \%)$ & \\
No. weaned & $3(3.4 \%)$ & $8(4.6 \%)$ & $2.50 \mathrm{~ns}$ \\
No. served $1-7$ days & & 131 & \\
No. served $>7$ days & 83 & $122(93.1 \%)$ & \\
Winter & $82(98.8 \%)$ & $9(6.9 \%)$ & \\
No. weaned & $1(1.2 \%)$ & & \\
No. served $1-7$ days & &
\end{tabular}

\footnotetext{
${ }^{1} 8.56$ is the $\chi^{2}$ table value, ${ }^{2}$ ns - Non-significant $(\mathrm{P}>0.05)$.

${ }^{3}$ Number of sows served as a percentage of the number weaned.
} 
Weaning-to-service interval (WSI) referred to the time between weaning and service periods that normally occurs within seven days. Sows that were served after seven days were termed to have a prolonged oestrus. Return-to-service was recorded when a sow was served but did not conceive. The distribution of sows served after weaning and sows returned to service during the three seasons are presented in Tables 2 and 3.

Table 2 shows that during early summer, $86.2 \%$ of the experimental group and $95.7 \%$ of the control group came into oestrus between one and seven days after weaning and were served. During late summer, $96.6 \%$ of experimental group and $95.4 \%$ of control sows came into oestrus between one and seven days after weaning and were served. During winter, $98.8 \%$ of the experimental group and $93.3 \%$ of the control sows had come into oestrus between one and seven days and were served. The chi-square test gave a chi-square value of 11.07 , which is more than the 8.56 required for significance at $\mathrm{P} \leq 0.05$, indicating a highly significant $(\mathrm{P}=0.005)$ seasonal effect. However, when performing a pair-wise comparison of pair of columns and rows, no significant differences were found. In early summer the chi-square value for the frequencies of the experimental and control group was 6.67 which was non-significant but showed a relatively strong tendency when compared to the tabled chi-square value of 8.56. According to Smith (2004) (M.F. Smith, Personal communication, ARC Biometry Unit, Private Bag X519, Silverton 0184), it often happens that the chi-square test shows significance but the pair-wise comparison does not show differences, because it is a stricter test. The differences obtained in early summer between the experimental and control groups can therefore be regarded as a strong tendency.

Table 3 Frequencies of sows kept under regulated $(10 \mathrm{~h})$ or natural photoperiod returning to service after being served less than seven days post weaning during different seasons

\begin{tabular}{lccc}
\hline \multirow{2}{*}{ Seasons } & \multicolumn{2}{c}{ Number of sows } & $\chi^{2}$-value \\
\cline { 2 - 3 } & Regulated photoperiod & Natural photoperiod & \\
\hline Early summer & & 149 & \\
$\quad$ No. conceived & 72 & $31(20.8 \%)$ & $6.90 \mathrm{~ns}^{2}$ \\
$\quad$ No. returned & $3(4.1 \%)^{3}$ & 137 & \\
Late summer & 77 & $30(21.9 \%)$ & $3.40 \mathrm{~ns}$ \\
$\quad$ No. conceived & $7(9.1 \%)$ & 112 & \\
$\quad$ No. returned & 76 & $10(8.9 \%)$ & $0.001 \mathrm{~ns}$ \\
Winter & $6(7.9 \%)$ & & \\
$\quad$ No. conceived & No. returned & &
\end{tabular}

${ }^{1} 8.56$ is the $\chi^{2}$ table value; ${ }^{2} \mathrm{~ns}$ - Non-significant $(\mathrm{P}>0.05)$.

${ }^{3}$ Number of sows served as a percentage of the number weaned.

During early summer $4.1 \%$ of the experimental group returned to service (Table 3) compared to $20.8 \%$ of the control group but the difference was not statistically significant. During late summer $9.1 \%$ of the experimental group returned to service compared to $21.9 \%$ of the control group. During winter $7.9 \%$ of the experimental group return to service compared to $8.9 \%$ of the control group. The chi-square test used also gave a chi-square value of 11.07, which is more than the 8.56 required for significance at $\mathrm{P} \leq 0.05$, indicating a highly significant $(\mathrm{P}<0.005)$ seasonal effect. However, when performing a pair-wise comparison of pair of columns and rows, no significant differences were found. In early summer the chi-square value for the frequencies of the experimental and control group was 6.90, which was not significant but showed a relatively strong tendency when compared to the tabled chi-square value of 8.56 .

The mean farrowing rates for the experimental and control groups of sows bred during different seasons are presented in Table 4 . The number of sows served was derived from the number served at $1-7 \mathrm{~d}$ after weaning plus the number served more than seven days after weaning.

The mean farrowing rate of sows bred in early summer for both the experimental and control sows was $95.4 \%$ and $81.3 \%$, respectively $(\mathrm{P} \leq 0.05)$. Farrowing rate of the experimental group was significantly higher compared to the control group. Sows of the experimental group bred during the late summer had a 
Table 4 Farrowing rates of sows kept under regulated $(10 \mathrm{~h})$ or natural photoperiod served during different seasons. $\chi^{2}$-value $=19.29$

\begin{tabular}{lccc}
\hline \multirow{2}{*}{ Seasons } & \multicolumn{2}{c}{ Number of sows } & \multirow{2}{*}{$\chi^{2}$-value } \\
\cline { 2 - 3 } & Regulated photoperiod & Natural photoperiod & \\
\hline Early summer breeding & 87 & 188 & \\
No. served & 83 & 152 & \multirow{2}{*}{$9.00^{*}$} \\
No. farrowed & $95.4 \%$ & $80.8 \%$ & \\
Farrowing rate & & 175 & \\
Late summer breeding & 87 & 141 & $3.79 \mathrm{~ns}^{2}$ \\
$\quad$ No. served & 79 & $80.6 \%$ & \\
No. farrowed & $90.8 \%$ & 131 & \\
Farrowing rate & 83 & 111 & $2.37 \mathrm{~ns}$ \\
Winter breeding & 77 & $84.7 \%$ & \\
No. served & $92.8 \%$ & & \\
No. farrowed & & & \\
Farrowing rate & &
\end{tabular}

${ }^{1} 8.56$ is the $\chi^{2}$ table value; ${ }^{2}$ ns - Non-significant $(\mathrm{P} \geq 0.05) ;{ }^{*}$ Significant $(\mathrm{P} \leq 0.05)$.

farrowing rate of $9.8 \%$ higher than the control group. This difference was not statistically significant $(\mathrm{P} \geq 0.05)$. Experimental sows bred during winter achieved numerically a $2.9 \%$ higher farrowing rate than the control group but these results were also not significantly different.

The number of piglets born per litter according to different breeding seasons of the experimental group kept at a regulated photoperiod $(10 \mathrm{~h})$ compared to the control group kept at a natural photoperiod is presented in Table 5.

Table 5 Mean number of piglets born ( \pm standard error) from sows kept under constant regulated $(10 \mathrm{~h})$ or natural photoperiod and served during different seasons

\begin{tabular}{lccc}
\hline \multirow{2}{*}{ Seasons } & \multicolumn{2}{c}{ Total born } & Seasonal \\
\cline { 2 - 3 } & Regulated photoperiod & Natural photoperiod & means $(\mathrm{P} \leq 0.001)$ \\
\hline Early summer & $11.4^{\mathrm{c}} \pm 0.29$ & $11.6^{\mathrm{bc}} \pm 0.20$ & $11.5 \pm 0.17$ \\
Late summer & $12.3^{\mathrm{ab}} \pm 0.29$ & $11.2^{\mathrm{c}} \pm 0.2$ & $11.6 \pm 0.17$ \\
Winter & $13.0^{\mathrm{a}} \pm 0.32$ & $12.4^{\mathrm{a}} \pm 0.26$ & $12.6 \pm 0.20$ \\
& & & \\
Treatment means & $12.1 \pm 0.17$ & $11.7 \pm 0.13$ & \\
$(\mathrm{P}=0.012)$ & & &
\end{tabular}

Interaction means were separated using Fisher's protected t-test least significant difference at $5 \%$ level of significance. Means followed by the same letter did not differ significantly at the $5 \%$ level.

Early and late summer means differed from winter, but not from one-another. The treatment $\mathrm{x}$ season interaction was significant $(\mathrm{P}=0.049)$. From sows bred during the early summer, the effect of constant reduced day light length on total born (11.4 and 11.6) per litter was not significant for experimental and control groups, respectively. For sows bred during the late summer season, the total number of piglets born per litter in the experimental group was higher $(\mathrm{P} \leq 0.05)$ compared to control group. For sows bred during winter, there was no difference in the number of piglets born. The mean number of piglets born per litter to the experimental group was 12.1 compared to 11.7 in the control group $(P=0.012)$ suggesting a significant photoperiod effect. The seasonal effects on litter size were also highly significant $(\mathrm{P}<0.001)$. Early and late summer means differed from the winter value, but not from one another. 


\section{Discussion}

Environmental factors such as photoperiod, temperature and housing are said to be playing an important role in the seasonal infertility of sows in many countries (Peltoniemi et al., 1999). The climate in the present study differed from other studies in temperate regions where the outdoor temperature is much lower and larger variations exist in the length of the photoperiod. For instance, in a study in Sweden, day length ranged from $5.9 \mathrm{~h}$ to $18.6 \mathrm{~h}$ (Tummaruk et al., 2000). Several studies showed that there is a seasonal effect on reproductive performance. These studies were conducted both in the arctic and sub-arctic regions of Norway on sows kept within the thermal neutral zone (Gaustad-Aas et al., 2004), a temperate region (Prunier et al., 1996) and the tropics (Tummaruk et al., 2007; Suriyasomboon et al., 2006). The present study has shown a seasonal effect on the reproductive performance of sows, measured as farrowing rate and litter size. The present study was conducted in a commercial piggery where it was unfortunately not possible to regulate temperature to the extent that it was kept constant (see Figure 1). According to Figure 1 the largest differences in temperatures between the experimental and control houses were $3.5^{\circ} \mathrm{C}$ and $4{ }^{\circ} \mathrm{C}$, recorded in January, February and March (late summer). Late summer breeding had no significant effect on the frequencies of service (Table 2), returns to service (Table 3) or farrowing rates (Table 4), suggesting that the difference in temperature could not have affected these parameters. It was also not possible to measure feed intake during lactation under the commercial conditions. Prunier et al. (1996) and Koketsu et al. (1997) suggested that part of the reproductive failure during summer could be attributed to nutritional deficiency due to lower intakes. The seasonality in reproductive performance of sows could therefore not be attributed to a single factor such as temperature or photoperiod, but there may be an interaction between the two factors. Litter sizes derived from late summer breeding were, however, significantly different between the treatment and control groups (Table 5). This suggests that constant photoperiod affects either the number of embryos or the survival of the embryos, and that there is a seasonal effect.

There was no significant difference between the experimental and control groups in terms of the frequencies of sows served within seven days and more than seven days post-weaning during any season, indicating that the regulated photoperiod had no effect on WSI. This is probably due to the fact that both groups of sows were kept under natural daylight conditions in the farrowing house and that the photo-effect of the dry sow house was not maintained until after weaning. The significant chi-square value indicates that at least the highest percentage differed significantly from the lowest. Therefore, when photoperiod was regulated at $10 \mathrm{~h}$ (experimental group) there was a significant difference in WSI between early summer and winter that may be associated with the fluctuating temperatures.

Seasonal infertility is characterized by return to oestrus after mating particularly in the period of 25 - 36 days post-mating (Love et al., 1993). In the present study a smaller proportion of the experimental sows returned to oestrus than in the control sows during early and late summer breeding (Table 3), although this difference was not significant, indicating that the reduced photoperiod during pregnancy had no effect on the frequencies of sows returning to service. McGlone et al. (1988) found that a long photoperiod (16 h light: $8 \mathrm{~h}$ darkness) in the farrowing house improved the return to oestrus of sows. This was also supported by the work of Stevenson et al. (1983). Long light duration on lactating sows has an indirect positive influence on the return to oestrus after weaning via an increase in appetite. It has been shown that pigs adjust their circadian melatonin secretion according to changes in photoperiod (Tast et al., 2001a). Bassett et al. (2001) found that melatonin implants which were inserted at the spring equinox were able to prevent seasonal anoestrus, thus providing further support for the contention that the duration of the daily photoperiod is the primary determinant of the reproductive seasonality. Contradicting findings were observed by Kermabon et al. (1995) who showed that a long light duration (16 h/day) had a detrimental influence on the return to oestrus after weaning, while a higher proportion of sows exposed to a short day length $(8 \mathrm{~h} /$ day $)$ exhibited oestrus shortly after weaning.

In the present study the increase in oestrus activity was observed in both groups with a WSI of less than seven days exhibited by sows. Although not significant, there was a strong tendency for sows in the control group during early summer to have a higher serving rate than the experimental group of sows. The reason for this is unclear. It may be only co-incidental. Many sows showed a high degree of synchrony of oestrus with five or six sows in adjacent pens being in oestrus during one day. The acceptable WSI that was achieved was probably as a result of the proper use of boars to detect oestrus. Such synchrony has been described in the European wild boar. Delcroix et al. (1990) have shown that ovarian activity in sows is as 
accurately synchronized in the absence as well as in the presence of boars. Such synchronization appears more likely to be a consequence of interactions between sows. Short photoperiods (10 h), as observed during winter season, were the best environmental condition for return to oestrus whereas long photoperiods $(13.4 \mathrm{~h})$ observed during the early summer and late summer season affected the return to oestrus in the control sows. The regulated photoperiod of $10 \mathrm{~h}$ was observed to reduce the return to oestrus of experimental sows during early and late summer, albeit non-significantly. Thus, the delay in return to oestrus after weaning in summer observed by numerous authors (Britt et al., 1983; Armstrong et al., 1986; Prunier et al., 1994) may be explained by the increase in light duration.

The present results demonstrate that regulated photoperiod similar to that of the winter season was more favourable and beneficial for farrowing rate during early summer breeding. According to observations by Cosgrove et al. (1993) the low farrowing rates indicate that pituitary support of the ovaries is at its weakest at the time when summer infertility is most frequent. Tast et al. (2002) reported that the maternal factors that could be considered to cause the low farrowing rate are failure of sows to respond to embryonic signals, regression of the corpus luteum because of inappropriate luteinizing hormone (LH) secretion, or inadequate endometrial secretion interfering with normal development of embryos and their ability to produce the oestrogen signals when needed. Luteinizing hormone secretion is known to be affected by seasonal variation (low in summer and high in winter) in the domestic pig (Peltoniemi et al., 1997a) and this seasonal variation appears to be controlled by photoperiodism through melatonin secretion (Bassett et al., 2001; Tast et al., 2001a). Therefore, the better farrowing rates achieved during the early summer in the experimental group when photoperiod was regulated compared to the control group is in accord with the observations of Bassett et al. (2001) and Tast et al. (2001a) in terms of the LH levels during different seasons.

Previous studies based on inter-oestrus-interval have suggested that the seasonal decrease in the farrowing rate was caused by the termination of established pregnancies (Love, 1981). Sows apparently conceive, have embryos present for a short period and then pregnancy is interrupted (Love et al., 1993). In a study by Love et al. (1993) lower farrowing rates were recorded in summer than in winter. In the present study the lower farrowing rates resulted from services in the periods where the photoperiod was longer and $10 \%$ higher farrowing rates were observed in the control group when served in winter (Table 4).

Additional evidence that reproductive seasonality underlies summer infertility was provided by measurements of levels of pituitary gonadotropin and LH in the studies by Lincoln (1992) and Peltoniemi et al. (1997a; 1999). It is significant that a decrease in LH concentration occurred at the same time as the frequency of disrupted fertility increased. However, the seasonal decrease in LH is not considered to be of sufficient magnitude to directly cause regression of the CL (Cosgrove et al., 1993; Peltoniemi et al., 1997b; Tast et al., 2001b). Although the seasonally diminished LH cannot directly cause regression of CL, it may decrease the progesterone secretion of the CL after it has become dependent upon pituitary LH support (Tast et al., 2002). Lowered progesterone levels might then change endometrial secretion in the uterus, causing a retarded development of embryos, which will in turn lead to a lower farrowing rate (Tast et al., 2002).

The improved farrowing rates observed during winter in both groups $(93.9 \%$ and $91.0 \%$, experimental and control, respectively) could be an indication that lower temperatures during winter had a significant effect. These results are similar to those observed in a study by Tast et al. (2002) who found that there was a higher farrowing rate $(72 \%)$ of sows served in winter compared to the farrowing rate in summer services $(63 \%)$ when the early disruption of pregnancy was investigated. In the present study, the difference of $3.4 \mathrm{~h}$ of photoperiod in early and late summer between the experimental and control groups may have affected the farrowing rate of the control sows.

Litter size in the experimental group of sows was similar compared to the control group served in early summer or in winter. In late summer the constant reduced photoperiod probably improved the litter size of the experimental group compared to the control group. Some studies have shown a seasonal effect on litter size. Peltoniemi et al. (1999) showed that litter size was smaller in summer breeding than in winter, whereas studies by Love et al. (1993) revealed that the litter size was not affected by season because a good litter size was observed in summer and winter. The results observed in this study show higher litter size in winter compared to other seasons with higher litter size in the experimental group compared to the control group. These results are in agreement with the results of Peltoniemi et al. (1999). 


\section{Conclusions}

The supply of constant $10 \mathrm{~h}$ photoperiod had no effect on the proportion of sows that were served within seven days or served after seven days, neither on the number of sows that returned to service. There was no seasonal effect on the proportion of sows served or on the proportion that returned to service. Farrowing rates were, however, improved by the supply of constant photoperiod housing during pregnancy although statistically only significant after early summer breeding. The net effect was seen in the number of piglets born. One piglet more per litter was born after winter breeding than after summer breeding. Regulated $10 \mathrm{~h}$ photoperiod for sows during gestation resulted on a average in 0.4 piglets more born per litter than for sows kept under natural photoperiod. This difference was 1.1 piglets per litter $(\mathrm{P} \leq 0.05)$ for sows mated during late summer. The supply of reduced constant photoperiod during gestation therefore seems to be a simple, cost effective environmental manipulation to improve reproductive performance. Further studies on the long-term effect of controlled photoperiod over several parities are needed.

\section{Acknowledgements}

The authors wish to acknowledge the cooperation and assistance of S.W. Janyk, A.T. Browne, J.M. Rust and M.F. Smith for support with statistical analysis of the data. Appreciation is expressed to the Humphries piggery, the Professional Development Program (PDP) of ARC and the Red Meat Research and Development Trust (RMRDT).

\section{References}

Armstrong, J.D., Britt, J.H. \& Cox, N.M., 1986. A seasonal differences in function of the hypothalamichypophysial-ovarian axis in weaned primiparous sows. J. Reprod. Fertil. 78, 11-20.

Bassett, J.M., Bray, C.J. \& Sharpe, C.E., 2001. Reproductive seasonality in domestic sows kept outdoors without boar. J. Reprod. Fertil. 121, 613-629.

Britt, J.H., Szarek, V.E. \& Levis, G., 1983. Characterization of summer infertility of sows in large confinement units. Theriogenology 20, 133-140.

Cosgrove, J.R., Urbanski, H.F. \& Foxcroft, G.R., 1993. Maturational changes in gonadotrophin secretion: the LH response to realimentation and nocturnal increment in LH secretion of feed/restricted pre-pubertal gilts. J. Reprod. Fertil. 98, 293-300.

Dan, T.T. \& Summers, P.M., 1996. Reproductive performance of sows in the tropics. Trop. Anim. Health Prod. 28, 247-256.

Delcroix, I., Mauget, R. \& Signoret, J.P., 1990. Existence of synchronization of reproduction at the level of the social group of the European wild boar (Sus scrofa). J. Reprod. Fertil. 89, 613-617.

Foxcroft, G.R., 1997. Mechanisms mediating nutritional effects on embryonic survival in pigs. J. Reprod. Fertil. 52, 47-61.

Gaustad-Aas, A.H., Hofmo, P.O. \& Karlberg, K., 2004. Reproductive performance of gilts and sows in temperate versus subarctic and arctic zones of Norway. Anim. Reprod. Sci. 80, 291-301.

Genstat for Windows, 2000. Release 4.2. 5th ed. VSN International Ltd., Oxford, U.K.

Kermabon, A.Y., Prunier, A., Djiane, J. \& Salesse, R., 1995. Gonadotropins in lactating sows exposed to long or short days during pregnancy and lactation: serum concentrations and ovarian receptors. Biol. Reprod. 53, 1095-1102.

Koketsu, Y., Dial, G.D. \& King, V.L., 1997. Returns to service after mating and removal of sows for reproductive reasons from commercial swine farms. Theriogenology 47, 1347-1363.

Lahrman, K. \& Gardner, I.A., 1997. [Epidemiological studies regarding the "summer infertility syndrome" of sows in confinement housing]. Dtsch. Tierartzl. Wochenschr. 104 (9), 383-386.

Lincoln, G.A., 1992. Photoperiod - pineal - hypothalamic relay in sheep. Anim. Reprod. Sci. 28, 203-217.

Love, R.J., 1981. Seasonal infertility in pigs. Vet. Rec. 109, 407-409.

Love, R.J., Evans, G. \& Klupiec, C., 1993. Seasonal effects on fertility in gilts and sows. J. Reprod. Fertil. (Suppl.) 48, 191-206.

Love, R.J., Klupeic, C., Thorton, E.J. \& Evans, G., 1995. An interaction between feeding rate and season affects fertility of sows. Anim. Reprod. Sci. 39, 275-284.

Malpaux, B., Wayne, N.L. \& Karsch, F.J., 1988. Termination of the breeding season in the Suffolk ewe: involvement of an endogenous rhythm of reproduction. Biol. Reprod. 39, 254-263. 
Malpaux, B., Viguie, C., Skinner, D.C., Thiery, J.C., Pelletier, J. \& Chemineau, P., 1996. Seasonal breeding in sheep. Anim. Reprod. Sci. 42, 109-118.

Malpaux, B., Thiery, J.C. \& Chemineau, P., 1999. Melatonin and the seasonal control of reproduction. Reprod. Nutr. Dev. 39, 355-366.

Mauget, R., 1982. Seasonality of reproduction in the wild boar. In: Control of Pig Reproduction. Eds Cole, D.J.A. \& Foxcroft, G.R., Butterworth. London. pp. 509-526.

McGlone, J.J., Wayne, F.S., Leland, F.T. \& Morrow, J.L., 1988. Photoperiod and heat stress influence on lactating sow performance and photoperiod effects on nursery pig performance. J. Anim. Sci. 66, 1915-1919.

Paterson, A.M., Barker, I. \& Lindsay, D.R., 1978. Summer infertility in pigs: Its incidence and characteristics in an Australian commercial piggery. Aust. J. Exp. Agric. Anim. Husb. 18, 698-701.

Peltoniemi, O.A.T., Love, R.J., Klupiec, C. \& Evans, G., 1997a. Effect of feed restriction and season on LH and prolactin secretion, adrenal response, insulin and FFA in group housed pregnant gilts. Anim. Reprod. Sci. 49, 179-190.

Peltoniemi, O.A.T., Love, R.J., Klupiec, C., Revell, D. \& Evans, G., 1997b. Altered secretion of LH does not explain seasonal effects on early pregnancy in gilts. Anim. Reprod. Sci. 49, 215-224.

Peltoniemi, O.A.T., Love, R.J., Heinonen, M., Tuovinen, V. \& Saloniemi, H., 1999. Seasonal and management effects on fertility of the sow: A descriptive study. Anim. Reprod. Sci. 55, 47-61.

Pepin, D. \& Mauget, R., 1989. The effect of planes of nutrition on growth and attainment of puberty in female wild boar raised in capacity. Anim. Reprod. Sci. 20, 71-77.

Peterson, A.M. \& Pearce, G.P., 1990. Attainment of puberty in domestic gilts reared under long-day or shortday artificial light regimes. Anim. Reprod. Sci. 23, 135-144.

Prunier, A., Dourmad, J.Y. \& Etienne, M., 1994. The effect of light regime under various ambient temperatures on sow and litter performance. J. Anim. Sci. 72, 1461-1466.

Prunier, A., Quesnel, H., Messias De Braganca, M. \& Kermabon, A.Y., 1996. Environmental and seasonal influences on the return to oestrus after weaning in primiparous sows. A review. Livest. Prod. Sci. 45, 103-110.

Quesnel, H. \& Prunier, A., 1995. Endocrine bases of lactational anoestrus in the sow. Reprod. Nutr. Dev. 35, 395-414.

Stevenson, J.S., Pollmann, D.S., Davis, D.L. \& Murphy, J.P., 1983. Influence of supplemental light on sow performance during and after lactation. J. Anim. Sci. 56, 1282-1286.

Suriyasomboon, A., Lundeheim, N., Kunavonkrit, A. \& Einarson, S., 2006. Effect of temperature and humidity on reproductive performance of crossbred sows in Thailand. Theriogenology 65, 606-628.

Tantasuparuk, W., Lundeheim, N., Dalin, A.M., Kunavongkrit, A. \& Einarsson, S., 2000. Reproductive performance of purebred Landrace and Yorkshire sows in Thailand with special reference to seasonal influence and parity number. Theriogenology 54, 481-496.

Tast, A., Hälli, O., Ahlström, S., Andersson, H., Love, R.J. \& Peltoniemi, O.A.T., 2001a. Seasonal alterations in circadian melatonin rhythms of the European wild boar and domestic gilt. J. Pineal. Res. 30, 43-49.

Tast, A., Love, R.J., Evans, G., Tesfer, S., Giles, R., Nicholls, P., Voultsios, A. \& Kennaway, D.J., 2001b. The pattern of melatonin secretion is rhythmic in the domestic pig and responds rapidly to change in day length. J. Pineal. Res. 31, 294-300.

Tast, A., Peltoniemi, O.A.T., Virolainen, J.V. \& Love, R.J., 2002. Early disruption of pregnancy as a manifestation of seasonal infertility in pigs. Anim. Reprod. Sci. 74, 75-86.

Tummaruk, P., Lundeheim, N., Einarsson, S. \& Dalin, A.M., 2000. Reproductive performance of purebred Swedish Landrace and Swedish Yorkshire sows: I. Seasonal variation and parity influence. Acta. Agric. Scand. Sect. A. Anim. Sci. 50, 205-216.

Tummaruk, P., Tantasuparuk, W., Techakumphu, M. \& Kunavonkrit, A., 2007. Age, body weight and backfat thickness at first observed oestrus in crossbred Landrace x Yorkshire gilts, seasonal variations and their influence on subsequence reproductive performance. Anim. Reprod. Sci. 99, 167-181. 